\title{
Fast Estimation of Relations between Aggregated Train Power System Data and Traffic Performance
}

\author{
Copyright (c) 2010 IEEE. Personal use of this material is permitted. However, permission to use this material for \\ any other purposes must be obtained from the IEEE by sending a request to pubs-permissions@ieee.org.
}

Lars Abrahamsson, Member, IEEE, Lennart Söder, Member, IEEE,

\begin{abstract}
Transports on rail are increasing and major railway infrastructure investments are expected. An important part of this infrastructure is the railway power supply system. The future railway power demands are not known. The more distant the uncertain future, the greater the number of scenarios that have to be considered. Large numbers of scenarios make time demanding (some minutes, each) full simulations of electric railway power systems less attractive and simplifications more so.

The aim, and main contribution, of this paper is to propose a fast approximator, that uses aggregated traction system information as inputs and outputs. This approximator can be used as an investment planning constraint in the optimization. It considers that there is a limit on the intensity of the train traffic, depending on the strength of the power system. This approximator approach is not encountered before in the literature.

In the numerical example of this paper, the approximator inputs are the power system configuration; the distance between a connection from contact line to the public grid, to another connection, or to the end of the contact line; the average values and the standard deviations of the inclinations of the railway; the average number of trains; and the average velocity of them, for that distance. The output is the maximal attainable average velocity of an added train for the by the inputs described railway power system section.

The approximator facilitates studies of many future railway power system loading scenarios, combined with different power system configurations, for investment planning analysis. The approximator is based on neural networks.

An additional value of the approximator is that it provides an understanding of the relations between power system configuration and train traffic performance.
\end{abstract}

Index Terms - railway, neural networks, load flow.

\section{INTRODUCTION}

\section{A. Outline of the Paper}

T HIS paper starts with an introduction, Section I, containing this outline and a motivation for the importance of this paper in particular.

The introductory section is followed by Section II. That is a section introducing RPSS:s (railway power supply systems). This is presented in order to make reading easier for persons with general electrical and mechanical engineering backgrounds but without experience in the railway-specific field. This introduction is supposed to give the reader a better feeling for the specific circumstances of a railway power supply system. That, in turn, would reasonably give a better understanding of the particular choices made for the approximator model design, and most important - the motivated need for the approximator. Readers familiar with railway power supplies, can skip Section II.

After that, Section III, which is a literature review of work that are somewhat related to dimensioning of power supply systems of railways, follows. First, the approximative models for calculating operation costs of electric railways known to the authors are mentioned. Second, different publications regarding decision making and planning for electric railways is presented. The section is concluded with railway power supply system operation simulators (RPSSOS:s), lectures and field overviews, and other research regarding the RPSS.

To our best knowledge, approximators of the kind presented in this paper have not been published in the literature. Neither have we heard any indications at visited conferences indicating that such approximators would already exist.

In Section IV, the model of the approximator is presented and motivated. Also assumptions needed for an approximator of this kind are motivated. The section also discusses the particular choices of inputs and outputs.

A numerical example is presented in Section $\mathrm{V}$, including neural network design and training details. Before presenting the performance of the approximator, the simulation data that is aggregated and used by the neural networks is presented and discussed. The neural network hidden layer sizes are motivated by plots analyzing the generalizing abilities of the neural networks used. Also summed square errors and the neural network weights are studied, as well as the training efforts needed by the computer used. An estimation of the importance of each input, given the used simulation data is also presented. Finally, some exemplifying plots are presented illustrating the neural networks in action. In those plots, also the training data is plotted.

The article is closed with Sections VI and VII presenting the summary and the conclusions of the paper, and some following discussions and suggested future work.

\section{B. Motivation of this Paper}

1) Power System Constraints that are Important for Investment Decision Calculations: This paper presents an approximator that rapidly estimates one of the three most important properties of an electric railway power supply system, when studying the future investment alternatives for the dimensioning of it.

The three most important such properties are: 
1) The railway peak power consumption, for each point of connection to the public grid, c.f. CE in Figure 1.

2) The energy consumption of the railway, for each point of connection to the public grid, c.f. CE in Figure 1.

3) The impact of contact line voltages on the maximal average velocity.

This paper studies property 3, more specific, the maximal average train velocity of a train inserted into an existing traffic plan.

The approximator presented in this paper models the train speed limits induced by the strength of the power supply system in combination of is loading, i.e. of the traffic itself. The aim of the approximator TPSA (Train Power System Approximator), is to obtain a fast estimation of at which speed trains can travel, given the power system configuration. The more power consumed, and the weaker the power system, the greater the voltage drops, and the thereby reduced tractive force of the trains. Thus, there is an obvious coupling between the optimal time tables and the power supply.

In this paper, the ideas of [1] are modified, improved, and more exact formulated. In [1], the power consumption of the railway was also estimated. Since this paper is more detailed, all focus is set on the maximal average train velocities as a function of the strength and the loading of the power system. Power and energy consumption can be treated separately in another study, since in [2] it has been shown that CE capacity and contact line voltage levels are not strongly correlated. One suggestion for a fast calculation of peak apparent power consumption and energy consumption is presented in [3].

2) Power System Constraints Needs to be Computed Easily and Fast: The main purpose for the development of TPSA is the need for having a fast approximative, but realistic way of calculating important operation costs for railway power supply systems investment planning. RPSSOS:s are good when just a small number of detailed studies are needed. However, when many systematic studies are needed, e.g. in scheduling and/or investment planning, detailed studies are too time consuming. The method needs to be fast because various combinations of train traffic situations and railway power supply system configurations may have to be tested against each other in a long-time stepwise investment planning for the railway power system, considering uncertainties in traffic levels, costs, etc. As stated in Section III-A, there are no fast approximators of the kind presented in this paper available today.

If using an RPSSOS as a part of the planning program, each iteration in such an optimization would involve RPSSOS usage. That would be far too inefficient. A typical RPSSOS run can take between one and three minutes for $160 \mathrm{~km}$ sections, whereas a greater part of the system can take hours. In e.g. [4] where planning is done by the help of a simulator, the calculations can take up to ten days with a deterministic model, not considering changes over time. Extending the problem to a stochastic yearly discretized model would increase the size of the problem, even more. This clearly shows the need of a faster method. In [5], the computation time savings by using neural networks are explained in detail.

3) Why Power System Constraints Could to be Represented by Neural Network: From the above and the literature review in Section III, one can conclude - in order to have humane computation times when optimizing the RPSS - some action has to be taken.

One option is to heavily simplify the RPSSOS. That can be done either by a detailed model that is simplified by a general function approximator like neural networks, or by simplified electric models that disregards important properties and relations. Whichever is to prefer in the general case is not obvious. In this case however, there is a need for considering the voltage level impacts on traffic. Then using a detailed RPSS model and simplifying the relations obtained seems to be the natural choice.

Another option seems to be using comparatively detailed models of RPSS as well as decision/planning model but using approximative and heuristic optimization algorithms. This option has not yet been considered by the authors.

4) Other Reasons for Approximator Usage: The most important reason to create TPSA, besides the computation speed, is that it is very convenient not having to do any train traffic simulations or power flow calculations when in an optimization program. To abstract the complicated reality with a few neural networks that simply can be treated as nonlinear constraints makes the decision and planning models cleaner and more surveyable.

Except being used as a part of an investment planning program, TPSA can be used as a constraint for the traffic when time tabling with care taken to the power system limits. This has not yet been found done in the literature, probably because of the complexity the problems would have.

Additionally, TPSA can be used as a scientifically developed rule of thumb for planner in the field, like a modernized version of the monographs in [6]. Looking at plots of TPSA keeping some inputs fixed gives rough ideas of what is possible or not for a certain power system configuration.

TPSA can also be used in a more approximative manner, as in [7] where traffic outside a particular RPSS section is assumed to be unaffected by delayed trains inside the section. That method gives rough ideas of where the power system is too weak, and has to be strengthened.

\section{RAILWAY POWER SUPPly SyStemS}

RPSS:s are by practical reasons rarely three-phase, but either single phase AC or DC systems. The AC systems are either operated at the same frequency as the public power grid or in a different frequency. If the frequency is different, it is normally a lower frequency. There are several different standards in voltage levels for the contact line for both the $\mathrm{AC}$ and the DC railway systems. The contact line delivers electricity to the trains, often as an overhead line called catenary. DC railway power supplies and AC power supplies with different frequency are similar in topologies, e.g. electric power has to be converted by power converters to be able to flow between the public grid and the railway grid. Doubly fed railway power supply system sections are connected as in Figure 1. The denotation Connecting Equipment (CE) is here used as a general name for the component that is either a converter station or a transformer connected to the threephase public grid. AC railway grids with public frequency 
simply have transformers instead of converter stations, using one or two of the public grid's three phases. In order not to cause asymmetrical loading, the public-grid phases connected to the public-grid-frequency railway grid, are altered for each consecutive transformer station. Therefore, because of the $120^{\circ}$ phase angle difference, in contrast to the configuration of Figure 1, the public-grid-frequency railway is never fed from more than one $\mathrm{CE}$ at once. For a public-frequency railway system, the contact line would have been sectioned where $Z_{2}$ is located in Figure 1. A more thorough overview of railway power supplies can be found in [8].

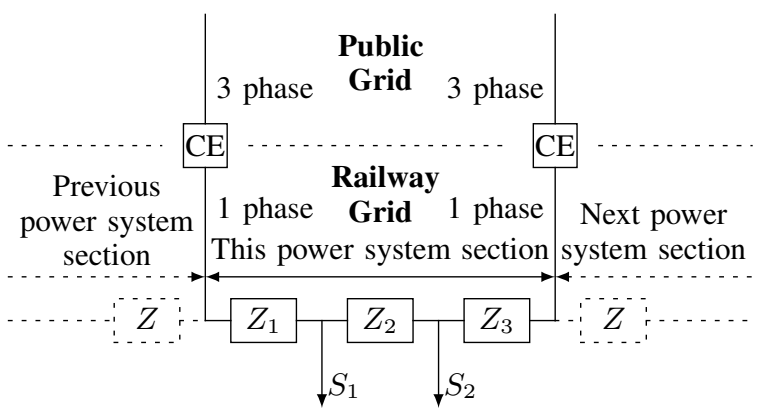

Fig. 1: A section of the railway power supply system, illustrated as an electric circuit.

\section{A. The Railway Grid Compared to the Public Grid}

RPSS:s differ in some ways from public power systems. One special property is that the loads vary heavily over time, in a complex way, both in load size and load location [9]. Normally, the voltage levels are allowed to vary to a much greater extent in the RPSS, compared to the public one. Locomotives are designed to accept substantial voltage drops to a greater extent. The level of acceptance varies greatly between different models. The Swedish Rc locomotive will still be in operation for voltage drops of about $40 \%$ [10].

Because of these great voltage variations, computing the load flows becomes more complicated, because a simple iterative algorithm is less likely to converge if the initial guess is too far from the true value [9]. Moreover, when electric nodes become too closely located, they have to be treated as one - otherwise the impedance matrices of the system would risk becoming close to singular [9]. In the general case, the problems can also be heavily nonlinear.

In order to be able to describe the variations in location and size of the loads, i.e. the trains, an RPSSOS software needs to consider a few details. An enough detailed simulation determines train locations, velocities, accelerations, contact line voltage levels, tractive efforts, and (if AC, active and reactive) power consumed. Inputs to such an RPSSOS are track inclinations, time tables, information about the power consumption of the electric motors of the trains and about the modeling of the CEs, impedance values for conductors, acceleration and speed-limits, running resistances, and weights of various trains.

\section{B. CEs, Power Transmission, and How to Strengthen the Grid}

The CEs ("CE" in Figure 1) of a railway power supply system, may it be transformers, frequency converters, or rectifiers, normally have some kind of voltage regulation on their railway side terminals. Therefore the closer located each pair of CEs are, the smaller the voltage drops on the contact line will be for a given load. Indeed, for singly fed contact lines (which is the normal case with AC railways in public grid frequency) the voltages will drop even more for the same CE-pair distance. Singly fed sections can, in DC systems and low frequency AC systems, for example occur at contact line ends, sectioning of the contact line for security reasons, or in cases of CE outages.

In some setups, the RPSS have own generation, and also regeneration from braking trains. In the 1970s when power electronics improved, it became possible regenerating energy from DC motors to AC power supplies [11], a feature not only saving energy, but also increasing the maximal braking torque. When a positive net production of power is possible on the railway side of the CEs, it is good if the CEs also allow power to be sent in the other direction.

Power is transmitted through contact lines, and if available, also HV (High Voltage) transmission lines and the transformers connecting them to the contact line. The transmitting impedances, $Z_{j}, j \in\{1,2,3\}$, are illustrated in Figure 1 , as the total impedances seen by the locomotives.

The power grid can be strengthened by placing the CEs closer to each other or by reducing the per-meter impedances between the CEs. Per-meter impedances between CEs can be reduced in many ways. Impedances can in $\mathrm{AC}$ systems be reduced by e.g. switching out BT contact lines (Booster Transformer [12]-[14]) for AT (Auto Transformer [12]-[15]) ones. Sometimes AT systems are also called dual systems or $2 \mathrm{xVL} \mathrm{kV}$ systems (where VL denotes the voltage level) [15]. There are also power-electronics based solutions with dual voltage contact line systems for DC railways [16]. Generally, conductors with less physical impedance, i.e. greater crosssectional areas or conducting materials with lower impedance, can be used. Another alternative is to connect HV transmission lines in parallel (or meshed as well when the topography so allows) to the contact line system.

A transformer station for an HV transmission line is normally cheaper to buy and operate than a converter station, so sometimes it might be better having a few strong converter stations and a number of transformers spread out between them, instead of having many weaker converter stations densely distributed with just the contact line connecting them. By natural reasons, the need for specific railway $\mathrm{HV}$ lines is smaller for AC railway power supply systems using the public frequency.

\section{Locomotives and Trains}

When traffic is dense, fast, and/or the trains are heavy, the power consumption of the trains is high. Then, eventually, the contact line voltage levels will drop. The trains are in Figure 1 represented by the $S_{j}, j \in\{1,2\}$ 
For most locomotives the maximal possible tractive force is successively reduced for decreasing contact line voltage levels by on-locomotive controllers. This control is installed due to physical limitations and regulations. It is done in order to protect the engine from overloading, and possibly also for reducing the risk of voltage instability in the RPSS. This voltage level dependency varies in details between different train models [17]. Some train models also have a velocity dependency of the maximal tractive force.

If the tractive force minus the running resistance and the gravitational resistance is above zero, the train accelerates. If, conversely, the net tractive force is below zero, the train will decelerate. The running resistance is mainly caused by wind resistance and mechanical resistance of the train, and is normally modeled as a second order increasing polynomial function of train velocity. The gravitational resistance is caused by train weight and the slopes of the railway track.

From the three above paragraphs it can be seen that, if the traffic increases faster than the strengthening of the power grid, the trains will sooner or later be forced to travel either more sparsely, more slowly, on other routes, with reduced weights, or combinations of these, compared to what they used to.

The tractive power is the tractive force times the train velocity. There are normally electrical and mechanical power losses inside the train. The (active) electric power consumption of the train is the tractive power plus power losses inside the train. In AC systems, if any reactive power is consumed, it can be caused either by the motor type, or by the desire of the operator to raise or lower the contact line voltage.

The railway administrator can choose when, and what kind of investments to make in the railway power supply. However, all the times when there are demand for a traffic that the power supply would not cope with - the administrator has to consider that fact.

\section{LiterATURE REVIEW OF VARIOUSLY RELATED WORK}

\section{A. Fast estimators of the railway power supply}

There are not so many existing methods for fast estimation of railway power supply system behavior known to the authors. The ones known are however discussed in the following.

Some efforts constructing an uncomplicated approximator, based on knowledge, intuition, and experience have been made in [18]. That paper presents a method to determine the minimum headway time, given the power system details as well as train data and the desired train velocity. In [18] however, the impacts of slopes are not considered, the power system is modeled very simple with assumptions not suitable for sparsely populated areas, and all the traffic is assumed to be homogeneous. Additionally, that approximator has not the same kind of input and output as required here.

In [5], the optimal point of coasting, considering the voltage drops and minimizing a trade-off between traveling times and energy consumption, is determined by using neural networks trained with simulation data as constraints in an optimization problem - quite similarly to what is done in this paper.

Neural networks are also in [19] used for estimating the voltage drops in the Bay Area Rapid Transit (BART) railway power system.
There is also a commercial software called OpenPowerNet available [20] that is a power system calculator connected to and communicating with Open Track (a railway operations simulator [21]) during simulation. The results from the power system calculations are considered in Open Track. The models of OpenPowerNet or Open Track are not available for the public. The approximator presented in this paper could be used similarly as OpenPowerNet, but as a part of an open source traffic planning software.

\section{B. Decision Making or Planning for Dimensioning of Power Supply Systems}

In [22], a beautiful algorithm for assigning locations of substations in a PRT (Personal Rapid Transit) system is presented. The objective is to minimize RPSS losses. It is not totally clear how the power consumptions are determined, and how they are smeared out into a so-called load power density on the power sections in [22]. The relation between voltage levels and tractive ability is not discussed.

In [23], RPSS:s are designed by making changes in the system setup and simulating once more until the system fulfils the demands of the designer. The more sophisticated methods for designing the power supply in [24], [25] are followups to [23]. In [24], where substations are placed out and catenary setup is chosen to minimize the investment cost, a simplified DC model of an AC RPSS is used, using a set of operational scenarios where power consumption is assumed to be known instead of simulating all the train movements. Besides that, in [24], there are constraints for voltage levels, power transmission in lines, and capacities of substations. In [25], a genetic algorithm is presented for solving the problem presented in [24], the results are not far from optimal and the computation time is significantly decreased.

In contrast to TPSA presented in this paper, where the maximal tractive force is slowly dropping off, in [24], [25] voltages are either such that no trains can operate, or such that all trains operate perfectly. Moreover, only train traffic snapshots are studied, and the power system models are simplified.

In [26], treating the optimal expansion planning of traction substations for DC networks, nothing is said about the simulation times. There, however the models seem simplified. As an example, in [26], first, the train traffic is simulated disregarding the power system limitations. First after that is done, mechanical power needed is used in the load flow calculations, and investments are made such that the voltage levels never goes under a certain threshold value, and then low levels close to the threshold are associated with a cost. It is not totally clear how the planning procedure in [26] works. Moreover, in [26] only worst case scenarios are studied. Worst cases may happen quite rarely, and sometimes low voltage levels may be a price worth to pay. The research project which TPSA is a part of aims to approach problems like when or how often, and for which traffic situations it may be worth having an imperfect power system. The operation costs, e.g. from delays, and investment costs have to be balanced somehow in real life. 
In [27], a tabu search algorithm is used for locating substations and setting the rectifier firing angles in an optimal way for DC traction systems with fixed train headways. The optimization in [27] is integrated with power system simulation instead of using snapshots in time. Tabu search is faster than standard optimization algorithms, but more approximative. Equal load sharing and minimizing energy usage are used as objectives. In [28], published before [27], the same objective is used, but the problem is solved with genetic algorithms. Here, the power consumption of trains is not voltage-level dependent and is determined in separate traffic simulations done before the optimization. In [27], the possible locations of substations are predefined, and not available on a continuous interval. The substations can be either regenerating or not.

In [29], the planning of where and when to invest in transformers feeding a DC RPSS is described. The transformers should be able to cope with the annual peak demand, and the investments and power losses are minimized. Simulink is used to determine train power consumption at each time snapshot. Power losses and investment costs in combination are minimized. Modeling details are however not presented in [29]. Still, the relation between maximal traction effort and voltage levels are explicitly pointed out in [29], which is the main focus in the TPSA presented in this paper.

In the, for the field early paper [6], nomographs are created by the use of simple power system models representing train traffic snapshots in time. These nomographs are supposed to be used as a hands-on support for engineers making decisions of where to locate railway power system substations.

In [30], the locations and sizes of harmonic filters are determined with the subject of reducing harmonic distortion in the railway power system.

\section{Railway Power Supply System Operations Simulators}

There exist a number of publications about RPSSOS of different kinds. Besides those, there also exist some commercial software - where, normally, the modeling documentation is not available for the public.

1) Commercial: The software originally developed by ABB as SIMTRAC, nowadays marketed by Balfour Betty Rail as TracFeed Simulation [31], [32] is still developed in Sweden by STRI. The program is used by e.g. the Norwegian and the Swedish railway authorities and some subway companies.

The by Siemens developed Sitras Sidytrac [33] is used internally in the Siemens corporate group.

ELBASTOOLS from the manufacturer ELBAS including SINANET (for DC traction), WEBANET (for AC traction), and IMAFEB/ELEFEB that is suitable to the calculation of effective overhead line impedances of AC railways as well as the magnetic and electric field distribution at cross sections around the contact and transmission lines [34].

The $\mu$-PAS, ZFS software from Prolitec AG, also exists as well as the software package Faber from Enotrac AG.

2) Academic: The simulation software TPSS (Train Power System Simulator), considering the interaction between the train traffic and the railway power supply system, is based upon consecutive load flows, calculated in discretized time.
In TPSS, the trains consider running resistance, slopes and gravity, and the limited tractive effort of train motors depending on low contact line voltages. The simulator also allows arbitrary CE models and considers various reactive power consumption schemes, often heavily nonlinear. TPSS is presented in detail in the full report [2], whereas some modifications and improvements are presented in [35]. In [36] TPSS was compared with the commercial software TracFeed Simulation [31], [32], and the relevant results were correlated between the programs.

In [37], a very early presented RPSSOS for DC rapid-transit railways, containing electric models considering voltage drop impacts on tractive ability, is presented.

One comparatively detailed $50 \mathrm{~Hz}$ RPSSOS working in discretized time is presented in [23], also considering phase imbalances in the public grid. All contact line voltages in [23] has to lie within a certain range. Other $50 \mathrm{~Hz}$ simulators are presented in [38], [39].

DC RPSS, subways in particular, including the interconnected supplying AC system has been modeled and studied in [40]. In the train models, the tractive capacity and the load of the trains are assumed to be independent of the state of the RPSS. The train distribution system and the transmission system are separated in the power flow computations, as are the conductor and rail impedances in the modeling. Similar modeling to the one found in [40] is presented in [41], but there the modeled DC RPSS is the Dutch public railway. The DC RPSSOS used in [27], uses predefined load locations determined by a train traffic simulation excepting the power system.

The AC and DC load flow calculations in [29] are done separately, first the DC railway load flow, then the AC supporting system, where the substations are modeled as fixed loads. In [42], the power flow between AC and DC is unified.

Different computation techniques exploiting the matrix sparsity for load flow in DC railways are discussed and presented in [43]-[45]. Also higher voltage RPSS have been studied [46]. In [47], harmonics in RPSS have been studied.

\section{Lectures and field overviews}

The broad lecture on electric railway systems, [8], explains most of today's RPSS standards and their technical, historical, and economical respective backgrounds.

In [48] different RPSS and their standards are explained with a focus on various DC systems and the $25 \mathrm{kV} 50 \mathrm{~Hz}$ system.

For another more general review (including different RPSS and other issues) of electric railway traction, please refer to [12], [49]-[54].

In [13], a brief but informative description of the Swedish RPSS can be found.

\section{E. Other railway power system research}

There are many published articles focusing on details of the RPSS. For dimensioning purposes however, it is enough keeping the steady state voltage levels as well as having capacity enough in converter or transformer stations. In [55], 
the rail impedance nonlinear dependency on frequencies is studied. Also in [56], [57] transient frequency dependencies of impedances are studied.

In [58], a detailed study of the crosstalk between adjacent railways tracks considering signalling and electromagnetic compatibility can be found. Magnetically induced contact line voltages are studied in [59].

In [60], the possibility to control substations for DC RPSS with thyristors in order to share the loads between the substations is treated.

Some articles consider the RPSS, whereas they keep focus on other things. In [61], instead of power supply investments, railway track investments are discussed, but the RPSS is also considered to some extent.

\section{THE APPROXIMATOR}

\section{A. Power System Sectioning}

1) Assuming the CEs can be Treated as Infinite Buses: Since the voltages normally are controlled at the railway side terminals of the CEs, it is in this paper assumed that the CEs can be approximated as infinite buses. That leads to a separation of the railway power system into many isolated and independent power system sections, whose borders are either CEs or simply the ends of the contact line.

2) Justification and Consequence of the Assumption: In [62], a simplification similar to the one just presented can be found. There, a train is assumed to consume power only from the feeder units right in front of, and right behind it. In [62], "feeder unit" means either a CE or a connection to an $\mathrm{HV}$ transmission line.

The power system sectioning assumption is an essential part of the TPSA model presented here. Its main benefit comes when considering the intended usage of TPSA. TPSA can, now that the power system has been split up into small pieces, easily be implemented as an optimization problem constraint. Such a constraint describes any traction power system section. The same constraint can even represent completely different neural networks. That property is of great value, as will be seen in Section IV-B. The separation of the RPSS into pieces makes the neural networks modeling more reviewable.

In [22], a similar sectioning of the power supply system is made. The motivation is however different, and a bit more complex.

3) Discussion about the Assumption: This is in most cases valid, since the states of the neighboring power sections normally do not affect the state of the studied section significantly.

In rare cases, like when the traffic is very unevenly spread over the power sections and if the CE capacities in the studied power section are comparatively weak, power may have to be taken from neighboring sections. With, e.g. the presence of an HV transmission line, the power sections become somewhat less isolated and independent.

Last, but not least, the possible accuracy losses can be compensated for afterwards by different means.

\section{B. Discrete TPSA Inputs Selecting which Neural Network to} Use

1) Model: All inputs to the neural-networks-based approximator TPSA are not neural network inputs. There are a few discrete variables that determine which of the available neural networks that should be activated.

The neural networks are only trained with inputs and outputs that can be regarded as continuous variables, i.e., "remaining inputs" in Figure 2. The remaining inputs are presented in Section IV-C.

In Figure 2, to illustrate, the two binary variables $\varrho$ and $\eta$ tells which of four available neural networks to be activated.

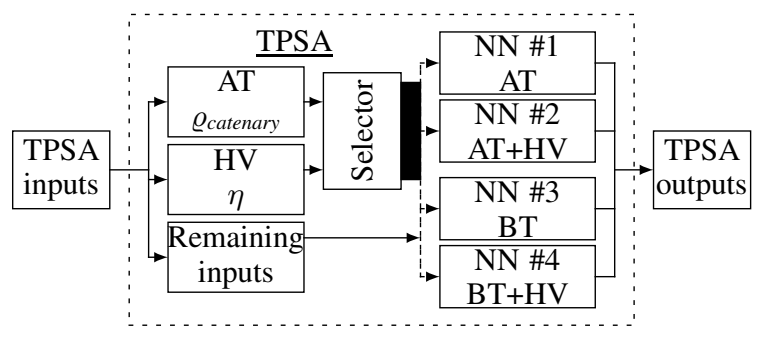

Fig. 2: For AT and BT contact line types, which can be either connected to or without an $\mathrm{HV}$ transmission line, there are four separate possible neural networks (NN).

The discrete TPSA inputs are listed in the following.

a) The binary variable, $\varrho$, tells whether or not the power system is equipped with an AT contact line system. If not, a BT contact line system is assumed. For DC systems, AT contact line system means a dual voltage system like in [16], and not AT means a normal DC system.

b) The binary variable, $\eta$, tells if there are HV transmission lines available or not.

2) Motivation: The separation into different neural networks is motivated by the fact that backpropagation [63], [64] networks are not optimal for discrete classifying variables. Backpropagation networks are mainly intended to be used as approximators of smooth functions.

The choices of discrete inputs are motivated in the following list.

a) Gives information about the distance-dependent impedances of the contact line system.

b) Gives information about the distance-dependent impedances between trains and CEs.

3) Discussion and Possible Future Work: Indirectly, in the model, it has been assumed that each power section has only one kind of contact line technology type (AT or BT, respectively). In real life, it happens, but is not very common that the contact line technology types change within the power sections. A future TPSA could include a method of managing this issue.

More discrete inputs than $\rho$ and $\eta$ might be needed in the future. To e.g. determine whether a power system section is doubly fed or singly fed is of importance for the strength of the section.

In the numerical example of this paper, all contact lines are doubly fed, so such input is not needed here. The numerical 
example is from a $16.7 \mathrm{~Hz}$ railway but it could - considering only the topology of the power grid and the principal behavior of the trains, i.e. disregarding the exact figures in $\mathrm{km} / \mathrm{h}$, minutes, etc. - also represent a DC railway system.

\section{Remaining TPSA Inputs, Continuous Inputs to the Neural Network}

1) Model: The remaining TPSA inputs follow in the below list.

a) The length of the power system section. That means the distance between a pair of CEs or between a CE and the end of the contact line.

b) The average inclination of the track between the power system section borders. The sign of the inclination is defined as it would have been experienced by the added train traveling all through the power system section.

c) The standard deviation of the inclination, in the power system section

d) The average number of (other) trains, $\gamma$, on the power system section. The average number of trains is here defined as the total already scheduled train traffic time in the power system section before adding train $r_{N}$, during the time window when the added train traffics the section, divided by the length of the same time window.

e) The average velocity of the other trains in the power system section in the above time interval, $v^{o}$. The average velocity is measured only when trains are moving.

2) Motivation: TPSA assumes a scheduling process, where an added train (train $r_{N}$ ) to the time table should not affect the state of the power system in such a way that the trains already scheduled (subset of trains $r_{1}, r_{2}, \ldots, r_{N-1}$ ) in the same power system section at the same time (as train $r_{N}$ ) should have to be rescheduled due to lost tractive capacity. The maximal speed of the added train can be seen as a measure of the traffic performance.

The idea is to describe the already scheduled trains in a lumped-together manner to the neural network of TPSA. There are two main reasons for this, of which the first one is the most important.

The first one is to keep the number of inputs to the neural network small. Many inputs increase the degrees of freedom. Like with polynomial data fitting, a network with many degrees of freedom demands a tremendous number of training cases in order to become reliable and generalizable. Training [63] means the iterative adjustment of the neural network parameters such that the network behaves as desired.

The second one is to have a constant number of inputs - regardless of the number of trains in the power section. There is no obvious theoretical upper bound on train density, so how many inputs that would be enough if treating all trains as individuals, is not obvious. Moreover, with the model suggested, assigning which train that should belong to which input, will not have to be an issue.

The inputs are motivated in the following list.

a) The distance gives information of the power system impedance. b) The average inclination gives information of the net potential energy consumed by the trains traveling within the section (more power consumed), but also on the aggregated running resistance for the studied train (more power consumed, and may also directly influence the speed).

c) The standard deviation of the inclination is needed because the average inclination is not informative enough. The average inclination would for example equal zero for both flat ground as well as for a steep uphill slope half the section and an equally steep downhill slope in the remaining half. The standard deviation is a measure of how much the inclinations fluctuate, which will influence the consumed electric power of the trains.

d) The number of trains is important because the more trains, the greater the need for electricity.

e) Not only the number of trains on a section determines their power consumption, but also their on-average velocities.

3) Discussion and Possible Future Improvements: In this paper, the model is restricted to one type of trains traveling in one direction. When there are trains with different mechanical and electrical properties in traffic, it might be necessary to have inputs for each train type, probably including the running resistance coefficients (see e.g. [65]) of the train type. Bidirectional traffic might also cause a need for extra inputs.

When TPSA is used in a time tabling program, inputs d) and e) in Section IV-C are sometimes depending on the output. The added trains traveling time is bounded below by, and therefore depending on, the maximal velocity, i.e. the output. At the same time the average number of trains, input d), and the average velocities, input e), are calculated by the use of the traveling time of the added train.

A sixth continuous input that describes the reduction of impedance by the transformers inside the section when there is an HV line present could be of need to be implemented in the future. This input will probably not be integer, because in reality the transformers are rarely evenly distributed. A continuous variable describing how well distributed the transformers are, is thereby expected to be needed.

Ohmic descriptions of power lines would introduce the ability of TPSA to judge between different kinds of BT and AT contact lines as well as HV lines. These have different per-km impedances.

\section{Output: The Fastest Possible Average Velocity of an Added Train}

1) Model: The output is the maximal possible on-average velocity of the added train, see Section IV-C.2.

2) Motivation: When creating a train time table, the scheduler needs to know the maximal possible on-average train velocity for each train. The reason why only average velocities are used is that it is common to model train time table planning programs [66]-[71] such that you know when and where the trains starts and stops - but nothing more. Obviously, only average train velocities can be used, and variations of the velocity between two train stops has to be unconsidered. 
The added train is by TPSA treated as an individual because there is no other way determining the maximal speed for each train.

3) Discussion: The output of TPSA tells at which maximal average velocity, $v_{\max }^{r_{N}}$, the added train is allowed to travel, for each given power system section, with a given track topography, and given that the then and there already scheduled traffic does not accept to consist of less than on-average $\gamma$ individual trains traveling in at least the average velocity $v^{o}$. This is, due to the lumping-together of the other trains, the closest to the desired goal of not rescheduling the existing traffic at all we can come.

In time tabling programs (except e.g. the commercial program OpenPowerNet [20]) the maximal velocities are fixed. In reality however, they are not. Voltage drops cause trains to go slower, as explained in Sections I-B, II-C. In order to simplify, instead of doing time tabling with variable speed-limits, a cost can be assigned to trains with reduced speed, as in [7].

\section{E. Summary}

The choices of aggregated inputs and output are adjusted for the kind of information that one can expect to be available from both detailed RPSSOS/measurements and train time table planning software. This does of course reduce the available choices for the design of the inputs and the output of the TPSA. Simulations/measurements are supposed to be used for the training data of the neural networks of the approximator. Simulators need to model the voltage drops at the contact lines, and their impact on the maximal train tractive force, to be useful for TPSA training.

\section{NumERICAL EXAMPLE}

\section{A. Introduction}

Two different neural network models are suggested and evaluated, both based on the output and inputs presented in Sections IV-B, IV-C and IV-D.

The first model, $M_{1}$, is a nonlinear neural network with two layers, expected to be enough for the purpose. The first (hidden) layer has tanh (tansig) transfer functions, a choice made based upon empiricism. The second (output) layer has a linear transfer function. There are five inputs, c.f. Section IV-C, and one output, c.f. Section IV-D. Nonlinear artificial neural networks, like $M_{1}$, can be used as general function approximators, given a sufficient number of neurons in the hidden layer(s) [72].

The second model, $M_{2}$, is a linear neural network. And since model $M_{2}$ is linear, adding more layers than the input and the output layers adds nothing to the neural network performance. The motivation for testing a linear model at all is explained by the intended use of TPSA in optimization programs. The accuracies of the two models are compared and evaluated in Section V-D.2.

\section{B. Training of the Neural Networks}

In both $M_{1}$ and $M_{2}$, the aggregated input and output data sets are normalized to lie in the interval $[-1,1]$ by simple scaling before training and testing the approximators.
Training is essentially a method of determining the values of the neural network parameters (weights and biases) such that the network behaves as desired. Commonly, this means that mean square of the estimation error of the network output is minimized, which is the case also here. Normally, the maximal number of iterations (epochs) is limited by the user and in this paper, the maximal number is set to one thousand for both $M_{1}$ and $M_{2}$.

Model $M_{1}$ is trained by the trainbr (Bayesian regularization backpropagation [73]) algorithm (of Matlab's Neural Network Toolbox) with an error goal of $10^{-5}$. The default training algorithm trainlm (Levenberg-Marquardt backpropagation [74]) has also been tried out, and in general it works as fine as trainbr. In some rare cases however, for the specific simulation data used, trainlm tends to overlearn the presented data rather than extracting the important trends from it. Model $M_{2}$ is trained by the trainb (batch learning [75]) algorithm (of Matlab's Neural Network Toolbox).

\section{The Used Training Data}

1) Introduction: The training data used for TPSA in this example are extracted out of TPSS [2] simulations. The simulations represent variations in traffic, length, and the power system technology of a typical Swedish RPSS section.

However, the training data could as well have been created from measurements and be representing different types of railway power systems than the one used here.

As a consequence of the Swedish-like model, the CEs, c.f. Figure 1, are here converter stations, and the high voltage line is of the in Sweden most common $132 \mathrm{kV}$ type. Since the Swedish system is AC, the contact lines can be of either AT or BT types. Contact lines and transmission lines are in Figure 1 represented by impedances.

2) Power System Infrastructure Used: In the simulations, each power section has the same contact line technology type (AT or BT, respectively) all over it, a consequence of the TPSA modeling. The simulated traffic is unidirectional.

In the Swedish railway power supply system, the defacto nominal contact line voltage level is $16.5 \mathrm{kV}$, however it is officially said to be a $10 \%$ over voltage in a $15 \mathrm{kV}$ system. The voltage angles at the converter station terminals are completely determined (although quite nonlinearly) by the voltage levels, and the active and reactive power flows in and out (if possible and allowed) of the terminals of the converter station [76]. And converter stations are injecting more power to the railway, the more installed power there is in the station compared to its neighboring stations.

The converter stations, the CEs in Figure 1, at both ends of each power system section are in the simulations equipped with six 10 MVA converters (Q48/Q49 [76]) each, i.e. $120 \mathrm{MVA}$ in total. That guarantees that the amounts of installed apparent power will not be a limiting factor in the simulations studied. Assuming about $4 \mathrm{MW}$ for each train, and an average velocity of $100 \mathrm{~km} / \mathrm{h}$ on a $160 \mathrm{~km}$ section and a headway, i.e. a train departure time distance, of 6 minutes gives around $65 \mathrm{MW}$ in total - allowing some reactive power consumption and transmission losses. 
It is here worth pointing out that in [2] it has been shown that the train velocities are in practice not dependent on the mutual distributions of apparent power capacity between a pair of converter stations, so these simulation results used for creating the training data are representative for all different variations of converter station capacities.

In the simulations with an $\mathrm{HV}$ transmission line present, the number of transformers connecting the transmission line to the contact line is set to three in all cases studied. This means that there are five transformers in total, three out on the track, and one connected to each converter station. The transformers are evenly distributed along the track.

3) Information About Trains Used: Since the model presented in Section IV assumed only one kind of trains, the simulations used one kind of trains as well - Rc4 [10] in this case.

Trains start and stop at the power section borders in the simulations. Since all systems here are double-fed, this means that a train starts at a converter station location and also stops at one. The term "double-fed" means here that a contact line is fed with power from not just one of its ends, but from both.

The speed-limit on the simulated track is in the simulations set as high as $150 \mathrm{~km} / \mathrm{h}$. That speed is for Rc4 locomotives a limiting constraint only in very steep downhill situations. There are in the simulations no train-individual speed-limits. All trains try to go as fast as possible in the TPSS simulations, i.e., as fast as the track speed-limits and the physical constraints of the railway in total allows. In the simulations used for creating the TPSA training data, the continually maximaltractive-force curve from [10] was used. A higher tractive force than the continually maximal-tractive-force may sometimes be used for shorter times without damaging the motors. However, the tractive force differs between the continually and the shorttime curves mainly for low velocities. Thereby, any maximalforce curve, results in similar simulation results, as another maximal-force curve would do, when there are not so many frequent stops and accelerations of the trains.

4) Description of Training Data Before Aggregation: A train has in a TPSS simulation been followed. An example of the world as it is seen by that train is visualized and presented in Figure 3. This is done in order to give the reader a picture of the behavior of the railway power system and what kind of simulator TPSS is.

At the same time interval, the summed active and reactive power consumptions of all trains in the same power section are plotted, together with the active and reactive power injections from the two converter stations, in Figure 4. All plots in Figure 4 are in per unit, with base power 5 MVA.

In that simulation, the power section length was $160 \mathrm{~km}$ on a BT system with HV line and the headway was 6 minutes. The velocity of the train, $v$, is in Figure 3 scaled down by a factor of $160 \mathrm{~km} / \mathrm{h}$. During this particular simulation, the studied trains speed varies between $151 \mathrm{~km} / \mathrm{h}$ downhill and $89 \mathrm{~km} / \mathrm{h}$ uphill. Additionally, Figure 3 presents the trains consumed active power, $P_{D}$, reactive power, $Q_{D}$, and the contact line voltage, $U$, all expressed in p.u., where the used base power $S_{b}$ is set to $5 \mathrm{MVA}$ and the base voltage level $U_{b}$ is the same as the nominal contact line voltage level, i.e.,

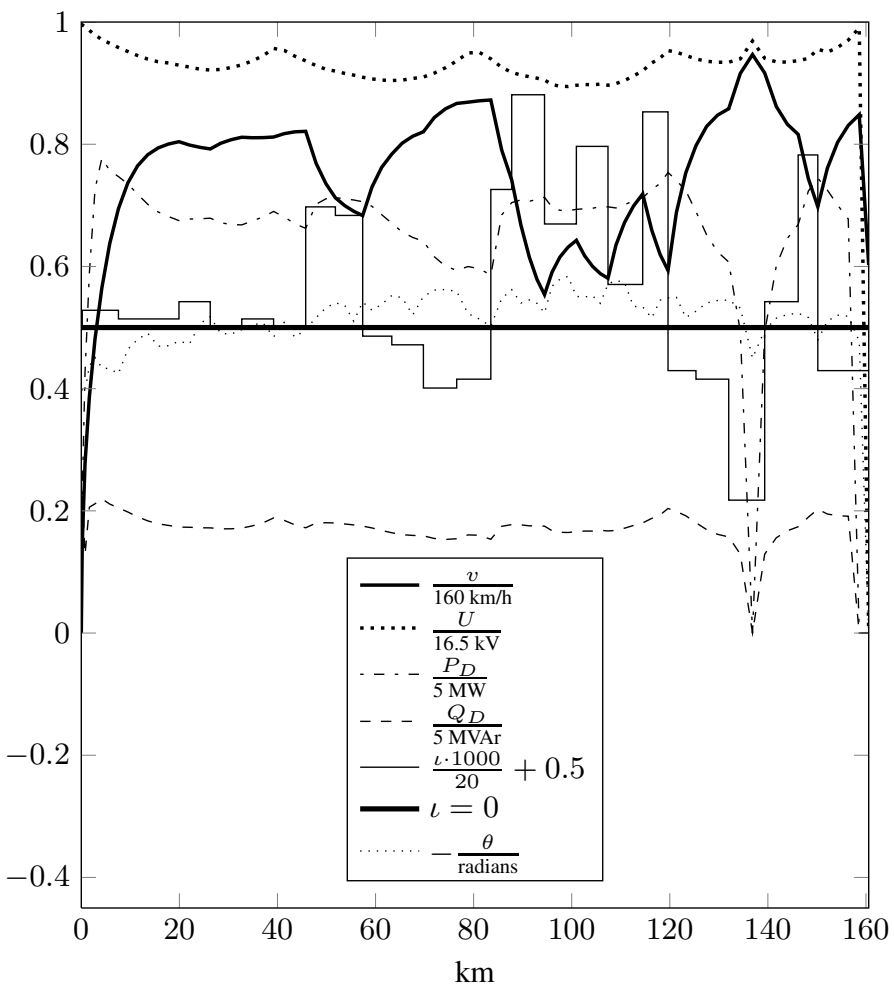

Fig. 3: An example of the mechanical and electrical states of a train traveling through a section of the railway electric power supply system.

$16.5 \mathrm{kV}$. The contact line voltage phase angles are in Figure 3 presented with opposite sign, i.e, $-\theta$, and expressed in radians. Finally, the inclinations of the railway track, $\iota$, are plotted in Figure 3 , scaled in such a way that the range $-10 \%$ (per mille) to $10 \%$ is depicted in the range 0 to 1 .

In order to save TPSS computation time when simulating a certain headway of the traffic, trains are evenly distributed along the track assuming that the trains have been going at maximally allowed speed all the time - disregarding possible slopes, air resistances, or weaknesses in the power supply. These trains are so to say, the initial condition of the simulation. This means that simulation results of the added train will be obtained all through the simulation. To study the filling-up of the track from a no-traffic situation is not of interest in this study. If filling the track up by simulations than this maximal-speed-assumed situation, the trains should have become slightly denser distributed along the track, since the velocities are reduced from time to time.

In the initial conditions, the distributed trains, assumed to already be in traffic, have velocities set to the maximal value. After the simulation has started however, the trains distributed along the track with predefined initial velocities will follow the same electrical and mechanical laws of nature as the other trains. Therefore, the number of trains within the section will slightly increase when their velocities goes down from ideal to real values. This fact explain the increasing trend of the curves in Figure 4. In the simulations, a steady-state of the train traffic is never reached. 


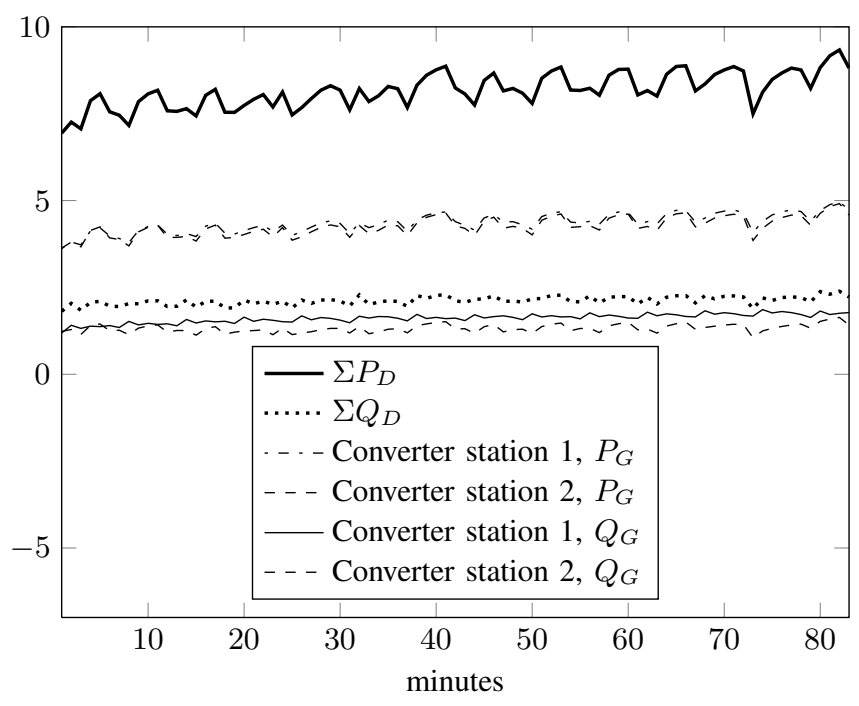

Fig. 4: An example connected to the one in Figure 3, the plot is for the same time window, and visualizes the total power consumption in the section and the power injected from the converter stations as functions of time.

5) The 400 training cases: In the numerical example, 400 different simulation results have been used, 100 for each neural network to train. There are four separate neural networks, one for BT-type contact lines, one for AT-type contact lines, one for BT with HV transmission line, and finally one for AT with $\mathrm{HV}$ transmission line - as described in Figure 2.

These 100 cases (for each power system type) consists of ten different power section lengths: $30,57,80,98,114,127$, $138,146,154$, and $160 \mathrm{~km}$. The simulations are done on the same rail section, with the inclination curve shown in Figure 3, where the first converter station is fixed in location at $0 \mathrm{~km}$, and the other one is moved as the power section length changes. These different power section lengths are in turn combined with ten different headway times of: $6,8,10$, $13,17,22,28,36,46$, and 60 minutes.

The case studies here have been selected to create significant voltage drops. Therefore, heavy trains with comparatively high running resistance have been used. Then, the main reason for not simulating headways shorter than 6 minutes is that with the heavy trains studied here, the voltage drops would be too great for BT-type contact lines in combination with long power sections. Moreover, the set of training data was purposely kept small to show the learning ability of the neural network. For lighter trains, and the same power supply, much shorter headways could be simulated, resulting in moderate voltage drops.

The power section lengths quite obviously make out input a) in Section IV-C. In this study, the variations in power section lengths also give rise to variations in inputs b) and c) in Section IV-C. That relation exists mainly because all simulations are here made on the same track. The headway times primarily gives rise to variations in input d) of Section IV-C, but also to e), to some extent.

\section{Evaluation of the TPSA Performance}

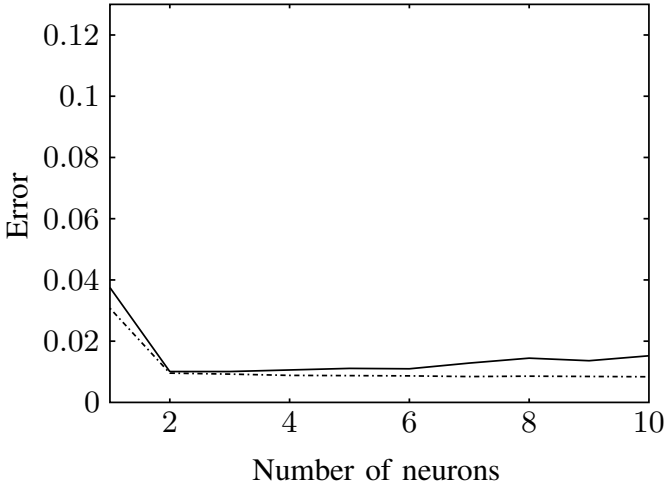

(a) AT-type contact lines and no HV lines

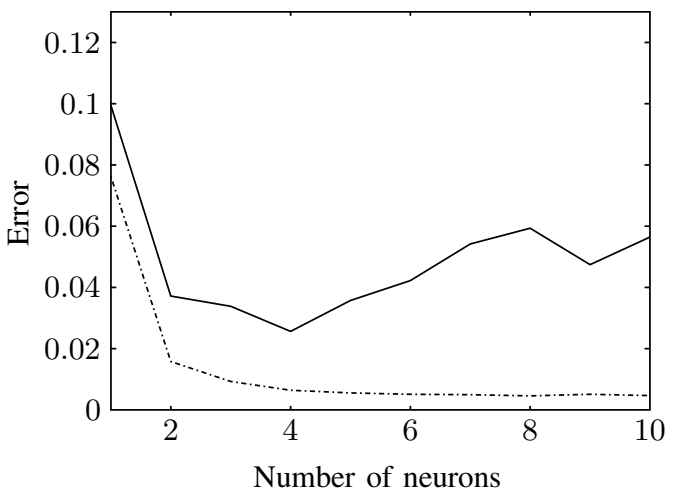

(b) BT-type contact lines and no HV lines

Fig. 5: A study of the average mean square errors on the training and testing sets as a function of the number of hidden neurons. Dash-dotted line denotes the training set curve and solid line denotes the test set curve.

1) Size of TPSA:s Neural Networks in the $M_{1}$ Nonlinear Model: As rule of thumb, during the evaluation of the neural network, two thirds of the data set may be used for training the neural network, whereas the remaining third may be used for testing. That proportion is used when evaluating which neural network size to chose in this paper as well.

By studying the average mean square approximation errors for one to ten neurons in the hidden layer, an idea of the right size of the neural network can be made. The average was calculated for 20 different random choices of training and testing sets. The results of the study are presented in Figure 5. In Figure 5b, it is shown that the errors in the testing set starts to increase for more than four hidden neurons for the BT contact line system. That phenomenon is due to overlearning and thereby lost generalization ability. In the three other, stronger, power systems, it is much easier predicting the maximal possible velocity since its values do not fall as fast as for pure BT systems. For different power system types, the maximal velocity of an added train as a function of the surrounding train traffic in the power section are illustrated in Figure 8 further down in Section V-E.2.

The number of hidden neurons for model $M_{1}$ was set to 4 , not only for pure BT, but for all types. The reason is that, the testing set errors are not decreasing for an increasing number of hidden neurons. The results for HV line together with BT- 
type contact lines as well as HV line with AT-type contact lines look similar to the pure AT results in Figure 5a. Too many degrees of freedom when fitting a function to measurements normally increase the variation of the function in an unwanted way.

2) Comparing the Nonlinear Model $M_{1}$ and the Linear Model $M_{2}$ : This part of the evaluation of the TPSA performance concerns a comparison of the accuracies of the two neural network models dealt with in this paper, the linear neural network, $M_{2}$, and the nonlinear neural network, $M_{1}$. Here, like in Section V-D.1 the comparison is made for both training and testing sets, and the results are averaged of 20 randomly chosen training and testing sets.

TABLE I: The approximation errors for the four different neural networks for model $M_{1}$

\begin{tabular}{cccc}
\hline \multicolumn{4}{c}{ Training Set } \\
\hline BT & AT & BT & AT \\
HV & HV & No HV & No HV \\
\hline $3.78 \cdot 10^{-3}$ & $6.04 \cdot 10^{-3}$ & $6.35 \cdot 10^{-3}$ & $8.17 \cdot 10^{-3}$ \\
\hline \multicolumn{4}{c}{ Testing Set } \\
BT & AT & BT & AT \\
\hline HV & HV & No HV & No HV \\
\hline $7.06 \cdot 10^{-3}$ & $1.37 \cdot 10^{-2}$ & $3.95 \cdot 10^{-2}$ & $1.23 \cdot 10^{-2}$ \\
\hline
\end{tabular}

The averaged mean square approximation errors for network $M_{1}$ are presented in Table I. The errors for network $M_{2}$ where about ten times the size of the errors of $M_{1}$. The computer time needed for execution of minor neural networks like these ones is negligible.

However, $M_{2}$, turned out to be of no use. When extending the training data set to the entire data set, the training algorithm of $M_{2}$ did not converge. To use all 100 cases for training of a network can be seen as there existed 50 additional simulation cases that the neural network should be tested against later. Therefore, $M_{2}$ is rejected as model candidate and will not be considered in the remainder of this paper.

3) Extra Evaluation of $M_{1}$ : The performance of the $M_{1}$ training are described in detail, for the 20 different, and randomly chosen training sets in Figures 6 and 7. In Figure 6, the summed squared weights and the summed squared errors of the neural network are plotted for each epoch. The figure shows that all 20 randomly chosen training sets converge well in training. That is seen by the fact that the weights converge in value, and the error go down to a level where they cannot be reduced more - and that is where the algorithm converges.

The training times in seconds, are shown in Figure 7 for the 20 different simulations. In the same plot, the number of needed iterations/epochs, divided by 100 , are also presented. The training times are in themselves not so interesting for the intended application of TPSA, since TPSA will ideally just be trained once, and then just used.

The weights in the hidden layer, $w_{k, l}$, where $k$ stands for input, and $l$ for neuron number have also been analyzed. By summing the squares of the weights, over the neurons, and taking the square root of that remaining vector, an idea of the

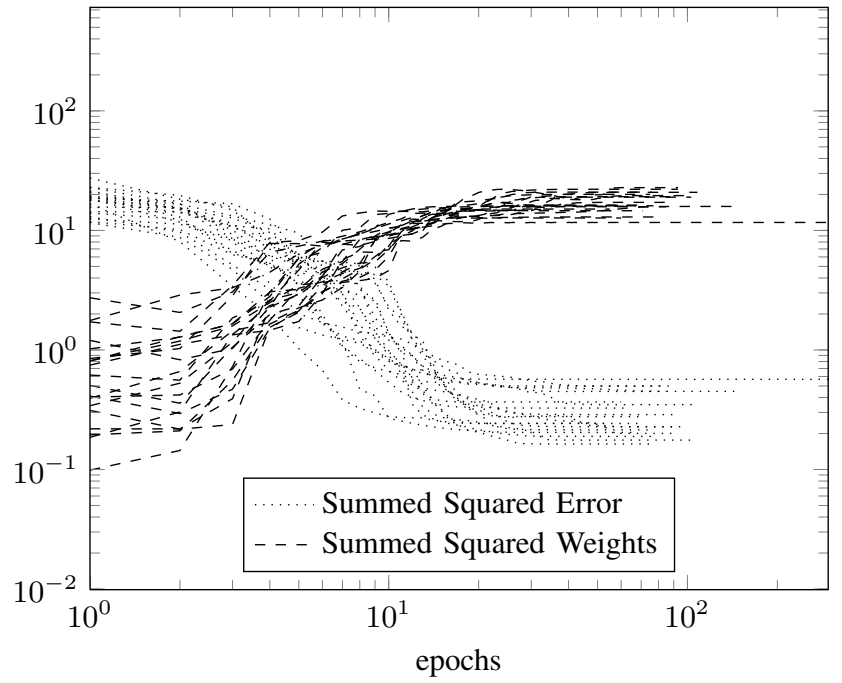

Fig. 6: Convergence graph of the summed square weight factors and the summed squared error for each iteration/epoch. The plots are for the 20 different and randomly chosen distributions of training and testing sets. The error graphs are, naturally, for the training set. The plot represents the neural network for BT-type contact line only. The graphs look similarly for the other kinds of power supply.

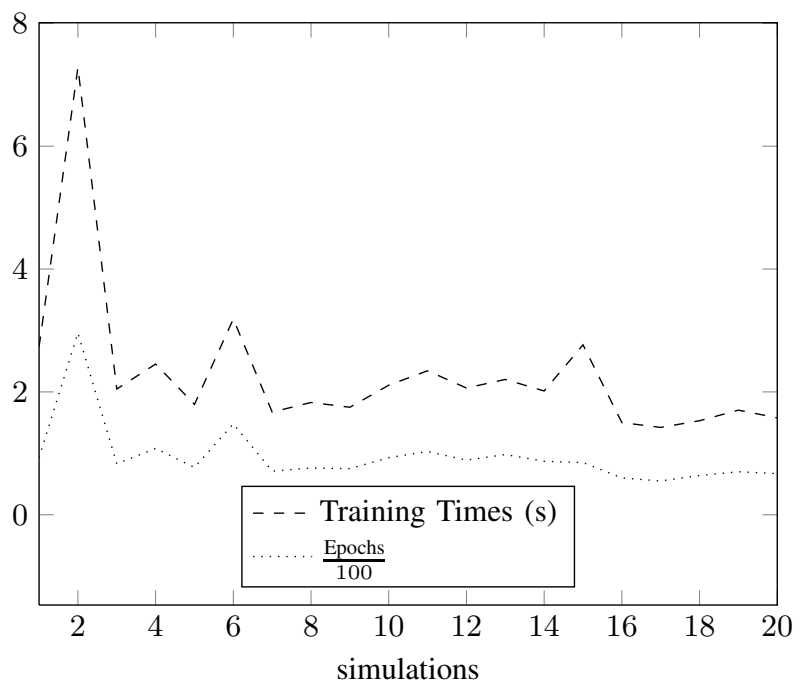

Fig. 7: In the above graphs, the learning times in seconds are plotted with the number of needed iterations/epochs for the training algorithm to converge. The graph is for pure BT and its corresponding neural network. The graphs for the contactline-only graphs looked about the same, and those with an HV transmission line present showed about the double in number of epochs and training times as the contact-line-only graphs.

importance of each input can be obtained,

$$
\sqrt{\sum_{l}\left(w_{k_{l}}\right)^{2}}=\left[\begin{array}{c}
0.94096 \\
0.80359 \\
1.3138 \\
0.83884 \\
0.43741
\end{array}\right]
$$


and the standard deviation of the inclinations seems to be the most important input, whereas the speed of the existing traffic is the least important. However, for a different, and especially greater data set the results could be altered.

\section{E. An illustration of TPSA in Practice; a Validation of TPSA} Interpolating and Extrapolating the by TPSS Generated Data

1) Prerequisites for the Detailed Study: Up to here, the design of the neural networks of TPSA has been determined, and the evaluation of TPSA has been done on a macroscopic level. Here, it is time to study details, i.e. the maximal possible velocity of the added train as a function of already existing traffic on the railway section.

In order to make the output of TPSA a function of one variable and thereby easier to illustrate and visualize, input e) in Section IV-C has been omitted. This is implicitly based on the assumption that knowing input $\mathrm{d}$ ), $\gamma$, means also knowing input e), $v^{o}$. When the train traffic is homogeneous it is close to the truth. Here, "homogeneous" means that all trains are: of the same kind, aiming to drive in the same velocity, and evenly distributed in time and space. After doing that, the neural networks of TPSA has been retrained with inputs a)-d).

This leaves four remaining inputs. All simulations are done on the same track profile, and inputs b) and c) of Section IV-C are completely determined by input a) in Section IV-C. This, together with keeping a) constant in the plots, gives one independent parameter per plot - as was the intention.

From Section V-E on, all the 400 cases of simulation data, are used for neural network training, in order to maximize the TPSA performance. In this study, besides the 400 cases, one extra training case has been added for each of the four networks and each of the ten power section lengths simulated, i.e. 40 extra cases. This is done because it became obvious that the available simulation data includes too few cases with really dense traffic for short power sections and for power sections with an HV line. When lacking data describing really dense traffic, it is very hard for TPSA to catch the strictly decreasing behavior of the added trains maximal velocity for an increased number of other trains. The added data says that the maximal velocity of the added train, $v_{\max }^{r_{N}}$, should be $0 \mathrm{~km} / \mathrm{h}$ when there already are 50 scheduled trains, $\gamma$. These figures are chosen in a way to force down the asymptotes of the $v_{\max }^{r_{N}}$ curves when traffic is high.

2) The Detailed TPSA Study: In Figure 8, the power section length is $160 \mathrm{~km}$ for all plots. In that figure, TPSA interpolates and extrapolates $v_{\max }^{r_{N}}$ as a function of $\gamma$. The four subplots, Figures $8 \mathrm{a}-8 \mathrm{~d}$ represent each of the four different power system technologies giving rise to different neural networks as explained in Section IV-B. As one can expect, and as Figures $8 \mathrm{a}-8 \mathrm{~d}$ confirm, the pure BT system is the one that creates the greatest drop in maximal train velocity for an increased number of trains on a section.

The longest power section where the TPSS calculations converged for all simulated headway times, also for the pure BT system, is $114 \mathrm{~km}$, c.f. Figure 9a. For $160 \mathrm{~km}$ power sections, pure BT simulations converged for headway times of thirteen minutes and longer. For a power section of $30 \mathrm{~km}$,

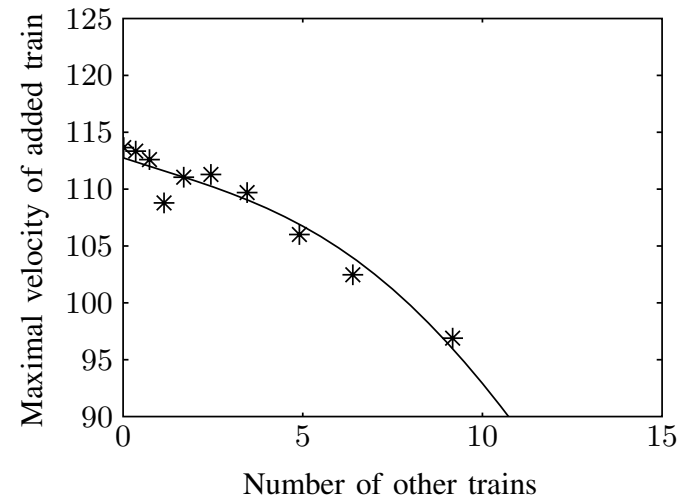

(a) BT-type contact lines and no HV transmission lines, the inter-converter station distance is $114 \mathrm{~km}$

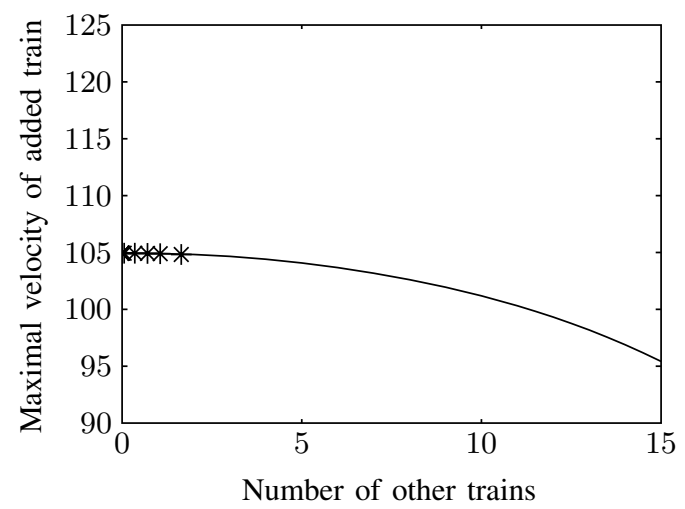

(b) BT-type contact lines and no HV transmission lines, the inter-converter station distance is $30 \mathrm{~km}$

Fig. 9: An illustration how $v_{\max }^{r_{N}}$ depends upon $\gamma$. The *s are TPSS results whereas the solid lines are TPSA outputs.

the velocities are, even for pure BT, quite unaffected by the densest traffic simulated, c.f. Figure 9b.

For really short power sections, $v_{\max }^{r_{N}}$ is comparatively low. For a lone studied train, $v_{\max }^{r_{N}}$ is $105 \mathrm{~km} / \mathrm{h}$ for a $30 \mathrm{~km}$ power section, c.f. Figure $9 \mathrm{~b}$, whereas for a $114 \mathrm{~km}$ power section, $v_{\max }^{r_{N}}$ goes up to $115 \mathrm{~km} / \mathrm{h}$, c.f. Figure $9 \mathrm{a}$. This can be explained by the fact that for short traveled distances the time it takes to accelerate the trains makes out a greater proportion of the total traveling time. Power section lengths of $80 \mathrm{~km}$ resulted in the highest train speeds for pure BT $(117 \mathrm{~km} / \mathrm{h})$ and AT $(119 \mathrm{~km} / \mathrm{h})$. The impedances grow too big for greater power sections - resulting in voltage drops and reduced tractive capacity.

\section{CONCLUSION AND SUMMARY}

In Section I the field of railway power supply dimensioning was introduced, and the importance of this paper was motivated. A literature review of relevance for this paper was presented in Section III. In Section II, railway power supply system models was discussed as well as a comparison between public grids and railway grids.

A suggestion to a new fast method, TPSA, of estimating the power system impact on traffic performance, has been presented in Section IV. The function approximator uses aggregated parametric values for inputs as well as for output. 


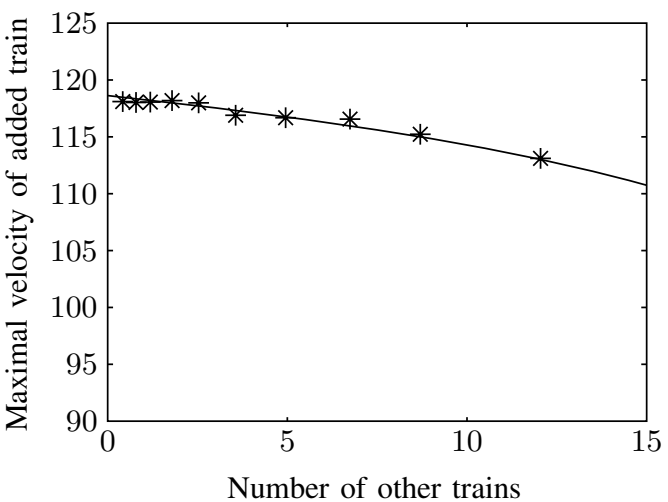

(a) AT-type contact lines and no HV lines

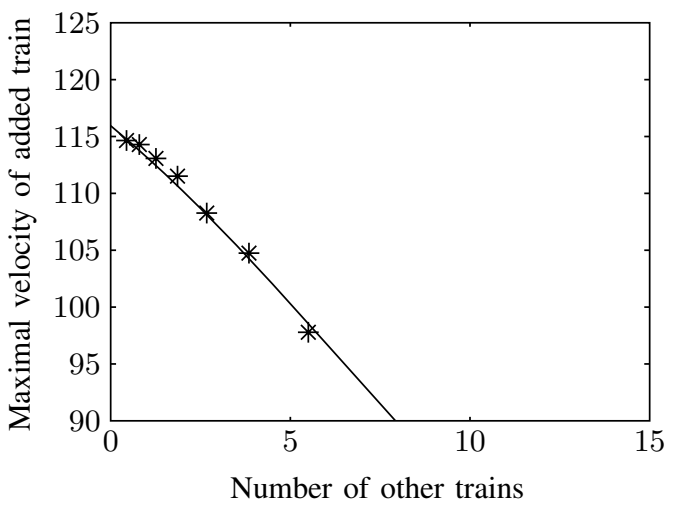

(c) BT-type contact lines and no HV lines

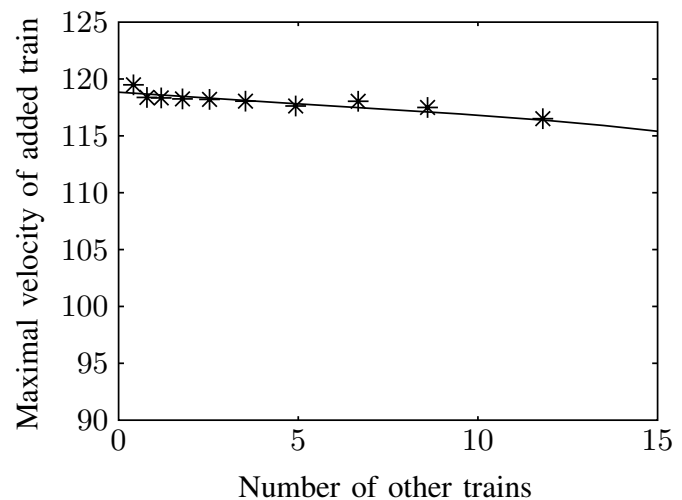

(b) AT-type contact lines and HV transmission lines

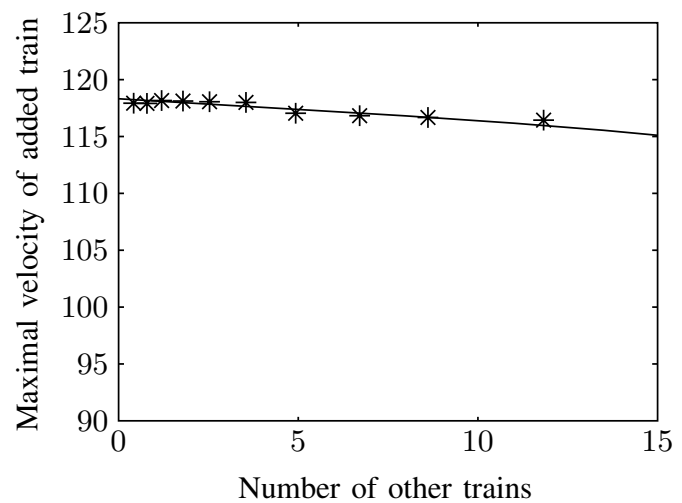

(d) BT-type contact lines and HV transmission lines

Fig. 8: An illustration how $v_{\max }^{r_{N}}$ depends upon $\gamma$ when the inter-converter station distance is $160 \mathrm{~km}$. The *s are TPSS results whereas the solid lines are TPSA outputs.

The proposed method is general in many ways. There are no indications that TPSA should not be possible to apply to other kinds of doubly fed RPSS:s (including doubly fed DC RPSS:s), than those used in the numeric example. TPSA has been applied to a small specific railway power supply system in order to confirm its usability.

TPSA was evaluated in Section $\mathrm{V}$, and a comparison between the two initially suggested approximator models $M_{1}$ and $M_{2}$ was presented, and $M_{2}$ was rejected as an alternative during the study.

For $M_{1}$, one hidden neural layer was assumed to be enough in all of the four neural networks. In that layer, four neuron were used. That choice worked fine with the data sets used, and not so many inputs. An example of the simulation results used were presented in graphs. Simulation data from 400 different, but systematically chosen cases were after proper aggregation used as TPSA training data.

Finally, in order to visualize the TPSS data trends, and how TPSA manages to adapt to them, a number of graphs in Figures 8 and 9 were presented and their content was discussed in detail in Section V-E.

It is obvious that TPSA manages to give reliable results in a fast way for given power system setups and traffic intensities.

\section{Discussions AND FUtURE WORK}

The results presented in this paper, show that by making many simulations (or detailed measurements) and studying the results - a feeling can be acquired for what is important regarding the railway power supply system and its interaction with the train traffic. Owing to that, the here presented approximator could be made.

Improvements in TPSA can be made in the sense that for more all-embracing data sets, different inputs would be possible, see the discussions in Sections IV-B.3 and IV-C.3.

Other future work are naturally to apply TPSA in investment decision programs, like in [7] but improved. TPSA can also be applied in traffic planning programs.

\section{REFERENCES}

[1] L. Abrahamsson and L. Söder, "Fast Calculation of the Dimensioning Factors of the Railway Power Supply System," in Computational Methods and Experimental Measurements, vol. XIII, Prague, The Czech Republic, Jul. 2007, pp. 85-96. [Online]. Available: http://www.ee.kth. se/php/modules/publications/reports/2007/IR-EE-ES_2007_019.pdf

[2] L. Abrahamsson, "Railway Power Supply Models and Methods for Long-term Investment Analysis," Royal Institute of Technology (KTH), Stockholm, Sweden, Tech. Rep., 2008, Licentiate Thesis. [Online]. Available: http://kth.diva-portal.org/smash/get/diva2:117/FULLTEXT02

[3] L. Abrahamsson and L. Söder, "Fast estimation of the relation between aggregated train power system information and the power and energy converted," in Universities Power Engineering Conference, 2008. AUPEC '08. Australasian, Dec. 2008, pp. 1-6.

[4] S. Methner, "Multicriterial Optimization for Elecric Railway Systems (original title in German)," Dresden University of Technology, Tech. Rep.

[5] S. Acikbas and M. T. Söylemez, "Coasting point optimisation for mass rail transit lines using artificial neural networks and genetic algorithms," IET Electric Power Applications, vol. 2, no. 3, pp. 172-182, 2008. 
[6] T. A. Kneschke, "Simple method for determination of substation spacing for ac and dc electrification systems," Industry Applications, IEEE Transactions on, vol. IA-22, no. 4, pp. 763-780, 1986.

[7] L. Abrahamsson and L. Söder, "Railway power supply investment decisions considering the voltage drops - assuming the future traffic to be known," in Intelligent System Applications to Power Systems, 2009. ISAP '09. 15th International Conference on, 2009, pp. 1-6.

[8] C. J. Goodman, "Overview of electric railway systems and the calculation of train performance," Electric Traction Systems, 2008 IET Proffessional Development course on, pp. 1-24, Nov. 2008.

[9] S. N. Talukdar and R. L. Koo, "The analysis of electrified ground transportation networks," IEEE Transactions on Power Apparatus and Systems, vol. 96, no. 1, pp. 240-247, Jan. 1977.

[10] N. Jansson, "Electrical Data for the Locomotive Types Rc4 and Rc6 (original title in Swedish)," TrainTech, Solna, Tech. Rep., Mar. 2004.

[11] T. Makino and K. Harada, "On the regenerative braking of dc motors with ac supply," IEEE Transactions on Industry Applications, vol. IA-10, no. 1, pp. 123-237, Jan./Feb. 1974.

[12] R. J. Hill, "Electric railway traction, Part 3 Traction power supplies," Power Engineering Journal, vol. 8, no. 6, pp. 275-286, Dec. 1994.

[13] A. Bülund, P. Deutschmann, and B. Lindahl, "Circuitry of overhead contact line network at swedish railway Banverket (original title in German)," Elektrische Bahnen, vol. 102, no. 4, pp. 184-194, 2004.

[14] J. D. Glover, A. Kusko, and S. M. Peeran, "Train Voltage Analysis for AC Railroad Electrification," IEEE Transactions on Industry Applications, vol. IA-20, no. 4, pp. 925-934, Jul./Aug. 1984.

[15] E. Pilo, L. Ruoco, and A. Fernndez, "A reduced representation of $2 \times 25 \mathrm{kv}$ electrical systems for high-speed railways," in Proceedings of the 2003 IEEE/ASME Joint Rail Conference, Apr. 2003, pp. 199-205.

[16] P. Ladoux, F. Alvarez, G. J. Herv Caron, and J.-P. Perret, "A new structure of power $1500 \mathrm{~V}$ catenary: the system $2 \times 1500 \mathrm{~V}$ (original title in French)," Revue Genrale des Chemins de Fer, vol. 21, pp. 21$31,2006$.

[17] S. Danielsen, F. Martinsen, and F. Johnsen, "Investigaton - Valuation of redundancy and dimensioning criterium for railway power supply (original title in Norwegian)," Norwegian national railway administration (Jernbaneverket), Tech. Rep. 200404562-17X, 2006.

[18] J. v Lingen and P. Schmidt, "Railway Electric Energy Supply and Operation of Railways (original title in German)," Elektrische Bahnen, vol. 96 , no. 1-2, pp. 15-23, 1998

[19] S. P. Gordon and D. G. Lehrer, "Coordinated train control and energy management control strategies," in Railroad Conference, 1998. Proceedings of the 1998 ASME/IEEE Joint, Apr. 1998, pp. 165-176.

[20] A. Stephan, "OpenPowerNet - simulation of railway power supply systems," in WIT Transactions on The Built Environment, vol. 103, 2008, pp. 449-459.

[21] "Railway Simulation," Apr. 2008. [Online]. Available: http://www. opentrack.ch/

[22] N. X. H. Viet, H.-S. Song, and K. Nam, "Optimal position finding algorithm for the power sources in the prt system," in Industry Applications Conference, 2003. 38th IAS Annual Meeting. Conference Record of the, 2003.

[23] E. Pilo, L. Ruoco, A. Fernndez, and A. Hernndez-Velilla, "A simulation tool for the design of the electrical supply system of high-speed railway lines," in Power Engineering Society Summer Meeting, 2000. IEEE, vol. 2, Jul. 2000, pp. 1053-1058.

[24] E. Pilo, L. Ruoco, and A. Fernndez, "An optimization procedure to determine the topology of ac railways power supply networks," in ASME/IEEE 2007 Joint Rail Conference and Internal Combustion Engine Division Spring Technical Conference, 2007.

[25] J. R. Jimenez-Octavio and E. Pilo, "Optimal design of power supply systems using genetic algorithms," in WIT Transactions on The Built Environment, vol. 103, Sep. 2008, pp. 391-400.

[26] H.-J. Chuang, C.-S. Chen, C.-H. Lin, J.-Y. Chen, and C.-Y. Ho, "Optimal expansion planning of traction substations for an electrified mass rapid transit system," in 2006 International Conference on Power System Technology, 2006, pp. 1-7.

[27] C. S. Chang, J. S. Low, and D. Srinivasan, "Application of tabu search in optimal system design and operation of mrt power supply systems," Electric Power Applications, IEE Proceedings, vol. 146, no. 1, pp. 7580, Jan. 1999.

[28] C. S. Chang, W. Wang, A. C. Liew, and F. S. Wen, "Bicriterion optimisation for traction substations in mass rapid transit systems using genetic algorithm," Electric Power Applications, IEE Proceedings, vol. 145, no. 1, pp. 49-56, Jan. 1998.
[29] C. S. Chen, H. J. Chuang, and L. J. Fan, "Unit commitment of main transformers for electrified mass rapid transit systems," Power Delivery, IEEE Transactions on, vol. 17, no. 3, pp. 747-753, 2002.

[30] H. J. Chuang, C. S. Chen, C. H. Lin, and H. M. Shiau, "Stochastic harmonic load flow analysis and distortion mitigation of mass rapid transit systems," in Power Tech Conference Proceedings, 2003 IEEE Bologna, vol. 3, Jun. 2003.

[31] J. Stern, "TracFeed Simulation, Reference Manual," Balfour Beatty Rail, Tech. Rep. BBSE951112-BNA, Mar. 2006.

[32] — , "TracFeed Simulation, User's Manual, Swedish Edition," Balfour Beatty Rail, Tech. Rep. BBSE951112-BRA, Mar. 2006.

[33] M. Altmann, B. Fiegl, M. Fihlon, M. Mokosch, and E. Schneider, "System design for the high speed line hsl-zuid with sitras sidytrac," in IEE International Conference on Railway Engineering, 2005.

[34] ELBAS Schweiz AG, "ELBAS Schweiz AG - NEWS," Jul. 2008. [Online]. Available: http://www.elbas.ch/EN/tool/toolMain.htm

[35] B. Boullanger, "Modeling and simulation of future railways," Master's thesis, Royal Institute of Technology (KTH), Mar. 2009. [Online]. Available: http://www.kth.se/ees/forskning/publikationer/modules/ publications_polopoly/reports/2009/XR-EE-ES_2009_003.pdf?l=en_UK

[36] I. Nordmark, "Comparative simulation and modelling of future railways electric power supplies (original title in Swedish)," Master's thesis, Uppsala University (UU), Jun. 2009. [Online]. Available: http://www-sml.slu.se/sve/es/exjobb/ingnor.pdf

[37] B. Mellit, C. J. Goodman, and R. I. M. Arthurton, "Simulator for studying operational and power-supply conditions in rapid-transit railways," Electrical Engineers, Proceedings of the Institution of, vol. 125, pp. 298-303, 1978.

[38] P.-H. Hsi, S.-L. Chen, and R.-J. Li, "Simulating on-line dynamic voltages of multiple trains under real operating conditions for ac railways," Power Systems, IEEE Transactions on, vol. 14, no. 2, pp. 452-459, 1999.

[39] R. J. Hill and I. H. Cevik, "On-line simulation of voltage regulation in autotransformer-fed ac electric railroad traction networks," Vehicular Technology, IEEE Transactions on, vol. 42, no. 3, pp. 365-372, Aug. 1993.

[40] C. L. Pires, S. I. Nabeta, and J. R. Cardoso, "Dc traction load flow including ac distribution network," IET Electric Power Applications, vol. 3, pp. 289-297, 2009.

[41] G. Hofmann, S. Rhlig, and A. Mom, "Calculation of DC Railway Grids with AC Supplying Grid Included (original title in German)," Elektrische Bahnen, vol. 7, pp. 254-258, 2000.

[42] Y.-S., "Unified ac/dc power flow for system simulation in dc electrified transit railways," Electric Power Applications, IEE Proceedings -, vol. 142, no. 6, pp. 345-354, Nov. 1995.

[43] Y. Cai, M. R. Irving, and S. H. Case, "Modelling and numerical solution of multibranched dc rail traction power systems," Electric Power Applications, IEE Proceedings, vol. 142, no. 5, pp. 323-328, 1995.

[44] C. J. Goodman and L. K. Siu, "Dc railway power network solutions by diakoptics," in Railroad Conference, 1994., Proceedings of the 1994 ASME/IEEE Joint (in Conjunction with Area 1994 Annual Technical Conference), Mar. 1994, pp. 103-110.

[45] Y. Cai, M. R. Irving, and S. H. Case, "Iterative techniques for the solution of complex dc-rail-traction systems including regenerative braking," Generation, Transmission and Distribution, IEE Proceedings, vol. 142, no. 5, pp. 445-452, Sep. 1995.

[46] M. Lehmann, "Railway Energy Supply with High Voltages (original title in German)," Verkehrswissenschaftliche Tage 28-29 September 2009, Sep. 2009.

[47] C. S. Chen, H. J. Chuang, and H. M. Shiau, "Stochastic harmonic analysis of mass rapid transit power systems with uncontrolled rectifiers," Generation, Transmission and Distribution, IEE Proceedings, vol. 150, no. 2, pp. 224-232, 2003.

[48] R. D. White, "Ac/dc railway electrification and protection," Electric Traction Systems, 2006. The 9th Institution of Engineering and Technology Professional Development Course on, pp. 281-322, Nov. 2006.

[49] R. J. Hill, "Electric railway traction, Part 1 Electric traction and DC traction motor drives," Power Engineering Journal, vol. 8, no. 1, pp. 47-56, Feb. 1994.

[50] _ - "Electric railway traction, Part 2 Traction drives with three-phase induction motors," Power Engineering Journal, vol. 8, no. 3, pp. 143152, Jun. 1994.

[51] — "Electric railway traction, Part 4 Signalling and interlockings," Power Engineering Journal, vol. 9, no. 4, pp. 201-206, Aug. 1995.

[52] _ "Electric railway traction, Part 5 Train detection, communications and supervision," Power Engineering Journal, vol. 10, no. 2, pp. 87-95, Apr. 1996. 
[53] - "Electric railway traction, Part 6 Electromagnetic compatibility disturbance sources and equipment susceptibility," Power Engineering Journal, vol. 11, no. 1, pp. 31-39, Feb. 1997.

[54] _ "Electric railway traction, Part 7 Electromagnetic interference in traction systems," Power Engineering Journal, vol. 11, no. 6, pp. 259266, Dec. 1997.

[55] R. J. Hill and D. C. Carpenter, "Modelling of nonlinear rail impedance in ac traction power systems," IEEE Transactions on Power Delivery, vol. 6, no. 4, pp. 1755-1761, 1991

[56] D. J. Tyvalsky, "Track/trolley system transients," IEEE Transactions on Industry Applications, vol. 24, no. 4, pp. 672-681, Jul./Aug. 1988.

[57] D. J. Tyvalsky and A. Y. Kulkarmi, "Inductance calculations for earthreturn trolley systems," in Industry Applications Society Annual Meeting, 1988., Conference Record of the 1988 IEEE, 1988.

[58] D. C. Carpenter and R. J. Hill, "Railroad track electrical impedance and adjacent track crosstalk modeling using the finite-element method of electromagnetic systems analysis," IEEE Transactions on Vehicular Technology, vol. 4, no. 4, pp. 555-561, Nov. 1993.

[59] B. Mellittt, J. Allan, Z. Y. Shao, W. B. Johnston, and C. J. Goodman, "Computer-based methods for induced-voltage calculations in ac railways," Electric Power Applications, IEE Proceedings B, vol. 137, no. 1, pp. 59-72, Jan. 1990.

[60] J. B. Flowers, "Load sharing with thyristor controlled rectifier substations," in Railroad Conference, 1995., Proceedings of the 1995 IEEE/ASME Joint, 1995.

[61] M. Wahlborg, "Simulation models: important aids for Banverket's planning process," in Computers in Railways V, Vol 1, Berlin, Germany, 1996.

[62] A. Nyman, "TTS/SIMON Power Log - a simulation tool for evaluating electrical train power supply systems," in Computers in Railways VI, Lisbon, Portugal, 1998.

[63] S. Haykin, Neural Networks. Englewood Cliffs: Prentice Hall, 1999.

[64] "Neural Network Toolbox (Matlab online help)," retrieved on March 9 2007, about backpropagation. [Online]. Available: www.mathworks. com/access/helpdesk/help/toolbox/nnet/backpro4.html

[65] P. Lukaszewicz, "Energy Consumption and Running Time for Trains," Ph.D. dissertation, Division of Railway Technology, KTH, Stockholm, Sweden, 2001.

[66] T. Lindner and U. T. Zimmermann, "Train Schedule Optimization in Public Rail Transport,” 2000. [Online]. Available: citeseer.ist.psu.edu/ lindner00train.html

[67] G. Sahin, R. K. Ahuja, and C. B. Cunha, "New Approaches for the Train Dispatching Problem," CORS/INFORMS Meeting, Banff, Alberta, Canada, May 2004.

[68] S. Harrod, "Optimal Scheduling of Mixed Speed Trains on a Single Track Line," Submitted in 2006, and revised for Transportation Science in 2007.

[69] A. Caprara, M. Fischetti, and P. Toth, "Modeling and Solving the Train Timetabling Problem," Operations Research, vol. 50, pp. 851-861, 2002.

[70] J.-W. Goossens, S. v Hoesel, and L. Kroon, "A Branch-and-Cut Approach for Solving Railway Line-Planning Problems," Transportation Science, vol. 38, no. 3, pp. 379-393, Aug. 2004.

[71] L. Ingolotti, F. Barber, P. Tormos, A. Lova, M. A. Salido, and M. Abril, "An Efficient Method to Schedule New Trains on a Heavily Loaded Railway Network," IBERAMIA2004, LNAI, vol. 3315, pp. 164-173, 2004

[72] K. Gurney, An Introduction to Neural Networks. CRC Press, 2003.

[73] "Neural network toolbox TM," Jul. 2008, about the "trainbr" training algorithm. [Online]. Available: http://www.mathworks.com/ access/helpdesk/help/toolbox/nnet/trainbr.html

[74] "Neural network toolbox TM," Jul. 2008, about the "trainlm" training algorithm. [Online]. Available: http://www.mathworks.com/ access/helpdesk/help/toolbox/nnet/trainlm.html

[75] "Neural network toolbox TM " Jul. 2008, about the "trainb" training algorithm. [Online]. Available: http://www.mathworks.com/access/ helpdesk/help/toolbox/nnet/trainb.html

[76] H. Kols, "Frequency Converters for Railway Feeding (original title in Swedish)," Swedish national railway administration (Banverket), Tech. Rep. BVH 543.17000, May 2004.

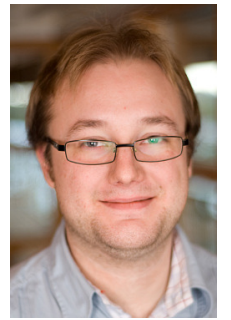

Lars Abrahamsson Lars Abrahamsson (M 06) was born in Luleå, Sweden in 1979. He received his M.Sc. degree in Engineering Physics from the Luleå University of Technology, Luleå, Sweden in 2005. $\mathrm{He}$ is currently a $\mathrm{PhD}$ student at the department of Electric Power Systems at the Royal Institute of Technology, Stockholm, Sweden.

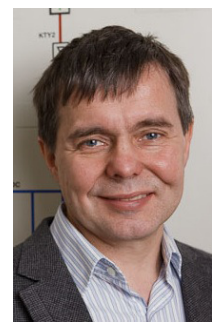

Lennart Söder Lennart Söder (M 91) was born in Solna, Sweden in 1956. He received his M.Sc. and $\mathrm{Ph} . \mathrm{D}$. degrees in Electrical Engineering from the Royal Institute of Technology, Stockholm, Sweden in 1982 and 1988 respectively. He is since 1999 a professor in Electric Power Systems at the Royal Institute of Technology. He also works with projects concerning deregulated electricity markets, distribution systems, power system restoration, risk analysis and integration of solar and wind power. 